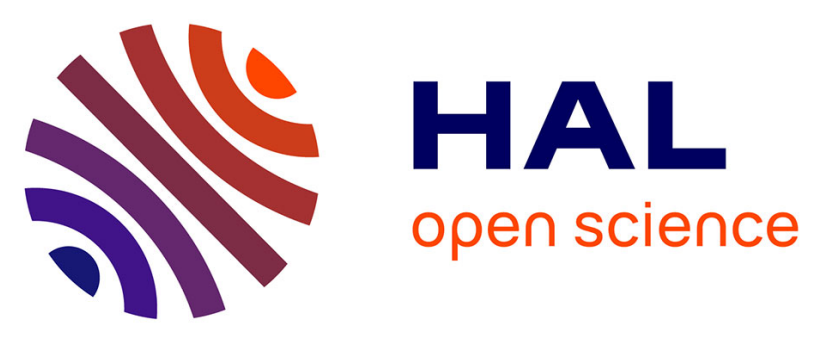

\title{
Computational fluid dynamics and septal deviations-Virtual surgery can predict post-surgery results: A preliminary study including two patients
}

Lionel Meister, Gilles Bouchet, Arthur Varoquaux, Jérome Giordano, Patrick

Dessi, Pierre Perrier, Justin Michel, Radulesco Thomas, Meister Lionel, Bouchet Gilles, et al.

\section{To cite this version:}

Lionel Meister, Gilles Bouchet, Arthur Varoquaux, Jérome Giordano, Patrick Dessi, et al.. Computational fluid dynamics and septal deviations-Virtual surgery can predict post-surgery results: A preliminary study including two patients. Clinical Otolaryngology, 2019, 45 (2), pp.286-291. 10.1111/coa.13495 . hal-03098597

\section{HAL Id: hal-03098597 https://hal.science/hal-03098597}

Submitted on 5 Jan 2021

HAL is a multi-disciplinary open access archive for the deposit and dissemination of scientific research documents, whether they are published or not. The documents may come from teaching and research institutions in France or abroad, or from public or private research centers.
L'archive ouverte pluridisciplinaire HAL, est destinée au dépôt et à la diffusion de documents scientifiques de niveau recherche, publiés ou non, émanant des établissements d'enseignement et de recherche français ou étrangers, des laboratoires publics ou privés. 
Computational fluid dynamics and septal deviations-Virtual surgery can predict post-surgery results: A preliminary study including two patients

Running title:

Authors:

Radulesco Thomas 1, 2, Meister Lionel 2, Bouchet Gilles 2, Giordano Jérome 2, Dessi Patrick ${ }^{1}$, Perrier Pierre ${ }^{2}$, Michel Justin ${ }^{1,2}$

Affiliation:

${ }^{1}$ APHM, Department of Oto-Rhino-Laryngology and Head and Neck Surgery, La Conception University Hospital, 13385 Marseille Cedex, France

${ }^{2}$ Aix-Marseille University, IUSTI, 13013 Marseille, France

CORRESPONDING AUTHOR

Thomas Radulesco

Address: Department of Oto-Rhino-Laryngology and Head and Neck Surgery, La Conception University Hospital, 147 Bd Baille, 13005 Marseille, France

Tel: +33491435858 Fax: +33491435810

Email: thomas.radulesco@ap-hm.fr

Keywords: CFD; nasal airway obstruction; virtual surgery; unsteady flow;

Funding source: none

Financial disclosure: none

Conflict of interest: none 
Nasal airway obstruction is a public health problem resulting in discomfort, manifested as a sensation of insufficient airflow through the nose (1). Septal deviation (SD) is one of the most common causes of nasal obstruction and SD's standard treatment is surgery (2).

CTscanner and rhinomanometry are currently most used examinations in the exploration of SD (3). Computational Fluid Dynamics (CFD) is a tool bringing new perspectives, allowing to model anatomy and airflows of sinonasal tract (4). CFD aims to study airflow and air conditioning and provides better understanding of nasal physiology.

Many CFD studies have been conducted in recent years (5). Correlations has been established between patient perception and CFD variables i.e. heat flux (6) (7). This reinforce the interest and validate the use of CFD. Moreover, 3D reconstruction tools make it possible to achieve architectural modifications and simulate surgical procedures: it's Virtual Surgery (VS)(8). Thus, association of VS and CFD may predict surgical outcomes and benefits of surgery (9).

However, CFD and VS currently raise two questions. Firstly, to date, most CFD studies were conducted in steady flow, a model of infinite inspiration (or expiration) which is different from physiological breathing (10). Unsteady flows are closer to reality but requires an increased computation time. Secondly, few CFD studies compared VS to postsurgery (PS) models (9). Establishing correlations between VS and PS would increase VS and CFD validity.

The main objective of our study was to compare VS and PS models using unsteady computations in a CFD study conducted on patients with SD. We also compared VS and PS to presurgery models. 


\section{MATERIALS AND METHODS}

\section{Ethical standards}

All patients gave written consent before participating in the study, which was conducted according to the Declaration of Helsinki. Authorization to conduct this study was obtained from local Ethical Committee (APHM N²017-14-12-005).

\section{Patient selection}

We included two patients referred in our Department for nasal obstruction, requiring septoplasty. Patient 1 (23-years-old men) was concerned with a major right-sided posttraumatic SD. Patient 2 (27-years-old female) had a congenital SD. Both were anterior rightsided and C-shaped SD according to Teixeira et al. or Radulesco et al. (2)(11). We used NOSE scores to assess patient impairment 1 month before and 6 months after surgery (12).

Preoperative CTscans were obtained using a low dose protocol on a multi-detector CTscanner (AquilionPrime, Canon Medical Systems, Otawara, Japan) using a cranio-caudal helical acquisition. In both patients, PS CTscans were performed at least 3 months after surgery and for another medical reason. PS CTscans did not show postoperative complication.

\section{Creation of 3-Dimensional Models}

3D reconstructions were obtained using ITK-Snap (3.6.0). The procedure was as follows: 1. Importation of CTscan images (DICOM formats), 2. Segmentation process using the half maximum height protocol (ImageJ software version 1.44) to determine the boundaries of anatomical structures, and 3. Nasal surface extraction. The half-maximum height protocol offers an objective process to delimit a reproducible interface between two tissues (13). This method included pixels from -1024 to -400 Houndsfield Units. Paranasal sinuses were removed manually during the segmentation process. 


\section{Virtual Surgery protocols}

In both cases, VS were blinded to operative protocol to avoid influencing anatomical modifications. VS were performed by another surgeon than the one who performed surgery using a combination of ITK-Snap $^{\circledR}$ and Star-CCM ${ }^{\circledR}$. By adding air voxels or performing millimetric translations, it was possible to create a new shape aiming to simulate a realistic surgical procedure (Figure 1). Time needed to perform the procedure were evaluated.

\section{CFD protocol}

CFD was performed using Star-CCM ${ }^{\circledR}$ software (Siemens ${ }^{\circledR}$ ). The computational domain was the Boolean union of extracted surface and a $3 \mathrm{~cm}$-diameter sphere centered on the tip of the nose. The aim of this sphere was to impose a pressure boundary condition far from the nostrils, thus allowing a non-imposed airflow close to the nasal entrance. Volume mesh was performed using a polyhedral mesher with parameters defined after a convergence mesh study: the prism layer (total thickness $=0.16 \mathrm{~mm}$ ) included 10 prismatic cells with 1.1 prism layer stretching ratio.

We defined the following computational hypothesis: airflow to standard conditions for temperature $\left(19^{\circ} \mathrm{C}\right.$ for inspiration, $37^{\circ} \mathrm{C}$ for expiration) and atmospheric pressure (101 $\left.325 \mathrm{~Pa}\right)$. Air was considered to be an incompressible Newtonian fluid with density $\rho=1.225 \mathrm{~kg} / \mathrm{m} 3$ and viscosity $\mu=1.8 \times 10-5$ Pa.s. We considered the flow to be laminar. Sinonasal surface was a nonslip wall. Wall temperature was $34^{\circ} \mathrm{C}(14)$. An imposed atmospheric pressure (reference value) was defined on the sphere surface.

In order to perform a time-dependent computation, a time-varying boundary condition applied to nasopharynx was previously recorded following a normal breathing cycle (Static pressure, Figure 2). $\mathrm{t}_{1}$ was maximum inspiration $(\Delta \mathrm{P}=-171 \mathrm{~Pa}$, time $=4.15 \mathrm{sec}), \mathrm{t}_{2}$ was the transition 
between inspiration and expiration $(\Delta \mathrm{P}=0 \mathrm{~Pa}$, time $=5.25 \mathrm{sec})$ and $\mathrm{t}_{3}$ was maximum expiration phase $(\Delta \mathrm{P}=+126 \mathrm{~Pa}$, time $=6.2 \mathrm{sec})$.

\section{Comparison between VS and PS}

Comparison between models were evaluated by searching differences and/or establishing correlations between CFD variables. We also compared nasal resistances, airflows and rhinomanometries.

\section{CFD variables measurements}

Heat flux, total pressure and wall shear stress were measurement averages within a circular wall region of $1 \mathrm{~cm}^{2}$. All measurements in axial view were performed $1.5 \mathrm{~cm}$ from the nasal floor on the lateral wall on 3 locations: location $\mathrm{n}^{\circ} 1$ was defined at the maximum SD, $2 \mathrm{~cm}$ after the entry of the nose (for both patients); location $n^{\circ} 2,4 \mathrm{~cm}$ after the entry of the nose; location $n^{\circ} 3$, at the choana $\left(7 \mathrm{~cm}\right.$ after the entry of the nose). Location $\mathrm{n}^{\circ} 0$ was ambient air values. Temperatures were mean temperature values recorded on cross sectional areas regarding locations $n^{\circ} 1,2$ and 3 . All these CFD variables were measured at $t_{1}, t_{2}$ and $t_{3}$ for each location $\left(n^{\circ} 1, n^{\circ} 2, n^{\circ} 3\right)$ on the most obstructed side (right side). We also analyzed streamlines.

\section{Nasal Resistances, airflows and rhinomanometries}

Nasal resistances and airflows were calculated for a static pressure differential of -75 Pa on the most obstructed side. Nasal resistances were expressed as $R=\Delta P / V$, where $\Delta P$ is the differential pressure between the nostril and the rhinopharynx and $\mathrm{V}$ is the airflow rate, expressed in Pa.s/mL.

Anterior Active Rhinomanometries (AA-RMM) (without vasoconstriction) were performed before and after surgery. The same rhinomanometer was used for both patients (Otopront ${ }^{\circledR}$, Rhinon-sys @ , Happersberger, Otopront GmbH2008). CFD-computed RMM curves (CFD-RMM) were performed before surgery, after VS and PS. 


\section{Statistical analyses}

A t-test was used to assess statistical differences between preoperative, VS and PS CFD variables according inspiration $\left(t_{1}\right)$ or expiration $\left(t_{3}\right)$ phases. $t_{2}$ measurements were not used for this statistical evaluation. $p$-values $<0.05$ were considered to be statistically significant.

The Pearson correlation test ( $r$ ) was used to assess correlations between VS and PS CFD variables using $t_{1}, t_{2}$ and $t_{3}$ measurements. Correlations were considered perfect if $|r|=1$, very strong if $|r|>0.8$, strong if $0.5>|r|>0.8$, moderate if $0.2>|r|>0.5$, low if $|r|<0.2$ and null if $r=0$. The 95\% confidence intervals of Person's rank correlation coefficients (IC95\%) were computed by bootstrapping using the RVAideMemoire package for R3.5 (R Foundation for Statistical Computing, Vienna, Austria). Correlations were statistically significant if $p<0.05$.

Statistical calculations were performed using PAST software (Oyvind Hammer, University of Oslo, Norway).

\section{RESULTS}

\section{Patient management}

A septoplasty with Killian incision through endoscopic approach was undergone in both cases. There was no complication after surgery. For patient 1, NOSE score was 70/100 before and 0/100 after surgery. For patient 2, NOSE score was 90/100 before and 0/100 after surgery. Our VS protocol aimed to simulate the septoplasty (Figure 1). VS duration were 6 and 26 minutes for Patient 1 and 2, respectively. 


\section{Comparison between CFD variables (Table 1)}

Regarding comparison between VS and PS models, we found no statistical difference regarding heat flux, wall shear stress, total pressure and temperature for inspiration and expiration phases (all p>0.05, Figure 3). Figure 4 shows evolution of temperatures for both patients. Concerning comparison between presurgery and PS or VS models, preoperative measurements were significantly different from VS and PS measurements during inspiration for heat flux, total pressure and temperature, but not for wall shear stress. We found no difference for expiration phase between models for all CFD variable (Figure 5).

The study of correlations between CFD variables of VS and PS models found very strong correlations for heat flux ( $r=0.93, \mathrm{IC} 95=0.78 ; 0.98)$, total pressure $(r=0.96, I C 95=0.87 ; 0.99)$, temperatures $(r=0.98, I C 95=0.95 ; 0.99)$ and wall shear stress $(r=0.92, I C 95=0.75 ; 0.97)$ (all $\mathrm{p}<0.01)$

\section{Nasal resistances and rhinomanometries (Table 2, Figure 6)}

VS and PS models provided comparable CFD-NR. Great improvement were found compared to preoperative evaluation in both cases. CFD-NR were quantitively different from rhinomanometry in most cases, while RMM curves shapes were comparable (Figure 6). For Patient 1 , the main difference was found regarding maximum pressures reached in preoperative AA-RMM compared to CFD-RMM (-600 Pa versus -171 Pa). For Patient 2, rhinomanometry showed still high nasal resistance postoperatively (1.04 Pa.s/mL).

\section{DISCUSSION}




\section{Synopsis of new findings}

CFD offers new perspectives in nasal airway analyses by visualization and measurements on airflow. With VS, the surgeon can try different corrections facing her/his technical possibilities. One of the major challenge for the surgeon is to choose which structure to modify, aiming the best outcome while seeking to be as conservative as possible(15). Indeed, extensive surgeries can lead to surgical complications such as empty nose syndrome or healing problems(16).

VS allows to visualize the impact of surgery. If computation time is still a major obstacle to realtime production of CFD models, in the near future, it will undoubtedly be possible to show to the patient which corrections would be feasible and their consequences on airflow. This could provide better preoperative information to the patient (Figure 7).

\section{Virtual Surgery protocols: clinical applicability}

Performing VS is fast and feasible whatever the SD. However, it requires learning the use of 3D reconstruction and CFD softwares (17). In our protocol, the correction of SD that did not come into contact with the lateral wall SD was easy using Star- $\mathrm{CCM}+{ }^{\circledR}$, applying progressive translations to walls (Patient 2). In case of contact between nasal septum and the lateral wall, it was more convenient to use the 3D-segmentation software by adding air voxels between structures (Patient 1).

\section{Reliability of Virtual Surgery}

Our study aimed to compare CFD variables between VS and PS. No differences were found for all CFD measurements between VS and PS. Moreover, we found great correlations between VS and PS for all CFD variables (Table 1). Finding close correlation coefficients appears logical since 
determination of heat flux, wall shear stress, temperature and total pressure are related to solving the same equations. This reinforce the validity of our measurement procedure.

Regarding inspiration phase, heat flux, total pressure and temperatures were greatly improved after surgeries. Surprisingly, differences for wall shear stress were not statistically significant although values of wall shear stress in location $n^{\circ} 1$ were frankly improved. This was related to wall shear stress measurements in Locations 2 and 3 that were almost equal for all models (Figure 8). As Li et al., focusing on maximal value of wall shear stress (Peak wall shear stress) could be more relevant when studying SD (18).

Comparing VS and PS models, the main difference for Patient 1 appeared in the upper and anterior part of the nasal fossa, where an indentation could be visualized postoperatively (Figure 3, black arrow). This was related to the surgical procedure. A higher correction of SD would have required an extra-corporeal septoplasty with open approach, but we believed our procedure would be compliant for the postoperative patient outcome. Looked in a different way, we may consider that VS overcorrected SD. Indeed, there is no anatomical or technical limit when performing a VS protocol. This explains why results could be slightly better after VS than PS, especially regarding total pressure and wall shear stress for Patient 2. VS protocols require surgical experience to remain realistic and avoid strong overcorrections.

Regarding expiration phase, no statistically significant differences were found for all CFD variables, nor between VS and PS, neither comparing presurgery to VS and PS. However, pressures variations in location $n^{\circ} 1$ decreased importantly after surgeries, testifying the correction of the anterior SD. We found few differences before and after surgeries regarding heat flux because nasal wall $\left(34^{\circ} \mathrm{C}\right)$ and expired air $\left(37^{\circ} \mathrm{C}\right)$ temperatures were close leading to a 
diminution of thermal exchanges compared to inspiration phase $\left(19^{\circ} \mathrm{C}\right)$. Otherwise, it appears logical that most of temperatures measurements in expiration phase were similar as SD were anterior. Studying CFD variables during expiration appeared less sensitive than inspiration values, matching with patient's complaint, almost only reported for inspiration.

Regarding rhinomanometries, we found good cohesions between VS and PS CFD-RMM. Most of differences were found regarding maximal pressures reached during $A A-R M M$, higher than in CFD-RMM. When performing AA-RMM, the patient had one-side nasal breathing and needed, because of their SD, an increased inspiratory effort $(\Delta \mathrm{P})$. In CFD models, patient had two-sided nasal breathing, leading to a diminution of airflow in each of the two nostrils, this artificially increasing nasal resistance. Deeper breathing cycle and unilateral nasal breathing should be used for a better comparison between rhinomanometries. For Patient 2, we found high nasal resistances with rhinomanometry after surgery (1.04 Pa.s $/ \mathrm{mL}$ ), although she had no nasal complain (NOSE $=0 / 100$ ). It has already been shown that quantitative comparison between rhinomanometry and patient reported outcome are low (19). Otherwise, nasal cycle, that was not assumed in our model, can lead to air pathway modification and could explain part of discrepancies between CFD-RMM and rhinomanometries. Some authors proposed virtual correction of nasal cycle: Gaberino et al. showed that correlations with patient perception improved after virtual correction of the nasal cycle (20)'(21).

The fact that most data between VS and PS were comparable provides scientific evidence of VS reliability. Other studies must to be carried out on this topic to consolidate these data.

\section{Contribution of unsteady computations}

To date, most of studies used steady flows, which correspond to an infinite inspiration (or expiration). This breathing model is quite far from a normal breathing which decomposes four 
phases: accelerating inspiratory, decelerating inspiratory, accelerating expiratory, and decelerating expiratory (22).

The main advantage of unsteady computation is to respect the normal breathing on the one hand, but also to provide visualizations close to reality showing inspiratory and expiratory airflows on the other (Video 1). The main disadvantage of unsteady computations is, to date, the computation time required to carry them out (about 5 days for 15 seconds computed). While waiting for computers improvement, steady computations, providing many information, remains possible. Differences between steady and unsteady computations must be explored in the field of nasal obstruction. Hörscher et al., in a preliminary study, found that major differences between steady and unsteady flows where found at transition from inspiration to expiration (23).

\section{Comparison with other studies}

Few studies evaluated VS in the field of nasal airway obstruction (8)'(9)'(24). If many have explored nasal physiology with CFD, this is the first, to our knowledge, to compare VS to PS with CFD variables such as heat flux or wall shear stress and using unsteady flows (7)'(25)'(26)'(27). Among existing studies, some focused on virtual turbinectomy (middle or inferior) and showed strong modifications in airflow and air conditioning (28), (29).

In the field of SD, Frank-ito et al. compared VS to presurgery and PS models studying nasal resistances, airflow and pressures in 10 patients (9). They found no statistically significant differences between VS and PS regarding unilateral nasal resistances $(p=0.059)$ and unilateral flow ( $p=0.074$ ). Comparing presurgery to VS or PS during inspiration, they always found statistically significant differences $(p<0.05)$. They also showed that their VS protocol had a tendency to overestimate surgeries outcomes on most obstructed side concerning airflows. In our study, VS overestimated anterior total pressure improvement (Locations $n^{\circ} 1$ and $n^{\circ} 2$ ). 
Rhee et al. tested different VS in a patient presenting multifactorial nasal obstruction and showed that most of the reduction in nasal resistance was accomplished with performance of septoplasty and inferior turbinate reduction (-50.2\% versus $-4.9 \%$ for nasal valve repair alone) (8). Obviously, everything depends on the model used. However, this is interesting and shows how, in the future, VS can help the surgeon in her/his therapeutic decision or surgical strategy. In a previously published study, Rhee et al. also showed that VS provided reliable results (30). Using VS, Garcia et al. showed that anterior SD are more involved in nasal obstruction than posterior's (24). However, these studies included only one patient, evaluated only nasal resistances, airflow or pressure measures in steady flows. Other CFD variables i.e. heat flux, are important to take into account while performing simulations and some authors highlighted how repetition of the respiratory cycle during simulation is essential to understand nasal physiology and avoid information loss (6)(7)(31).

\section{Perspectives}

Using unsteady flows brings CFD closer to reality. However, many progresses remain to be made. Some authors incorporated humidity in CFD models (32). Hygrometry must be taken into account toward humidification remains one of the first functions of the nose and could play a major role in nasal patency. CFD-calculated humidity may be correlated to patient perception, especially in case of empty nose syndrome.

The most important challenge is the creation of deformable model. During breathing, architectural modifications appears during inspiration and expiration. More or less important according to patients, cartilages and soft tissues deformability has already been tested in vivo and is characterized by the Young's modulus (33)(34). We are currently working on a deformable CFD model. 
Otherwise, this technology needs automating to be achievable in clinical routine. Deep learning techniques could help for the model reduction of the Navier-Stokes equations for unsteady flow problems (35). When incorporating these advancements, combination of VS and CFD could be, in the near future, an unavoidable tool for the ENT surgeon.

\section{Limits}

Our study included only two patients. This was due to the lack of postoperative CTscans. Indeed, all CTscans were performed for another reason after surgery, as we do not perform postoperative imaging for nasal airway obstruction.

Moreover, computation time are still long. However, steady computations are much faster and can be realized, upon request, in case of challenging situation. This is our practice today.

\section{CONCLUSION}

VS and PS models provided comparable results, matching with the clinical evaluation of our patients. In the near future, CFD and VS could be important tools to master for the ENT surgeon. Nowadays, we believe that CFD allows to better understand nasal physiology and to anticipate the surgical strategy to adopt before surgery for selected cases. 
Pearson correlation coefficient

\begin{tabular}{|c|c|c|c|c|c|c|}
\hline \multirow{2}{*}{$\frac{\text { Statistical test }}{\text { Data }}$} & \multicolumn{3}{|c|}{$\mathrm{t}$ test } & \multicolumn{3}{|c|}{ (VS / PS) } \\
\hline & & $p$ values & & r & IC95\% & $p$ values \\
\hline & & Inspiration $\left(\mathrm{t}_{1}\right)$ & Expiration $\left(t_{3}\right)$ & & & \\
\hline \multirow[t]{3}{*}{ Heat flux } & VS / PS & 0.7 & 0.9 & 0.9361 & $0.78 ; 0.98$ & $<0.01^{*}$ \\
\hline & Pre-op / VS & $0.01 *$ & 0.2 & & & \\
\hline & Pre-op / PS & $0.03 *$ & 0.17 & & & \\
\hline \multirow[t]{3}{*}{ Total pressure } & VS / PS & 0.17 & 0.9 & 0.96 & $0.87 ; 0.99$ & $<0.01^{*}$ \\
\hline & Pre-op / VS & $0.009 *$ & 0.19 & & & \\
\hline & Pre-op vs PS & $0.014^{*}$ & 0.14 & & & \\
\hline \multirow[t]{3}{*}{ Temperature } & VS / PS & 0.07 & 0.6 & 0.98 & $0.95 ; 0.99$ & $<0.01^{*}$ \\
\hline & Pre-op / VS & $0.007^{*}$ & 0.6 & & & \\
\hline & Pre-op / PS & $0.008^{*}$ & 0.1 & & & \\
\hline \multirow{3}{*}{$\begin{array}{c}\text { Wall shear } \\
\text { stress }\end{array}$} & VS / PS & 0.6 & 0.054 & 0.92 & $0.75 ; 0.97$ & $<0.01^{*}$ \\
\hline & Pre-op / VS & 0.2 & 0.23 & & & \\
\hline & Pre-op / PS & 0.1 & 0.2 & & & \\
\hline
\end{tabular}

Table 1. Statistical analyses comparing CFD Variables according to inspiration or expiration phases and locations. Statistical tests included CFD values of Patient 1 and 2. Pre-op= preoperative. VS = Virtual Surgery; PS = Postsurgery;

* statistically significant test 


\begin{tabular}{ccccccc} 
& \multicolumn{3}{c}{ Patient 1 } & & \multicolumn{3}{c}{ Patient 2 } \\
& Preop & VS & PS & Preop & VS & PS \\
\hline Nasal Resistances & 3.52 & na & 0.29 & 1.43 & na & 1.04 \\
Airflows & 21.3 & na & 262 & 41 & na & 74 \\
\hline CFD-NR & 13.9 & 0.32 & 0.28 & 0.78 & 0.35 & 0.34 \\
CFD-Airflows & 5.38 & 230 & 267 & 95 & 213 & 218
\end{tabular}

Table 2. Values of inspiratory nasal resistances and airflows on the obstructed side obtained with anterior active rhinomanometry (top) or CFD (bottom), for a pressure differential of -75 Pa after VS and RS. Nasal resistances in Pa.s/mL, Airflows in $\mathrm{mL} / \mathrm{s}$ 


\section{FIGURE LEGENDS}

\section{Preoperative}
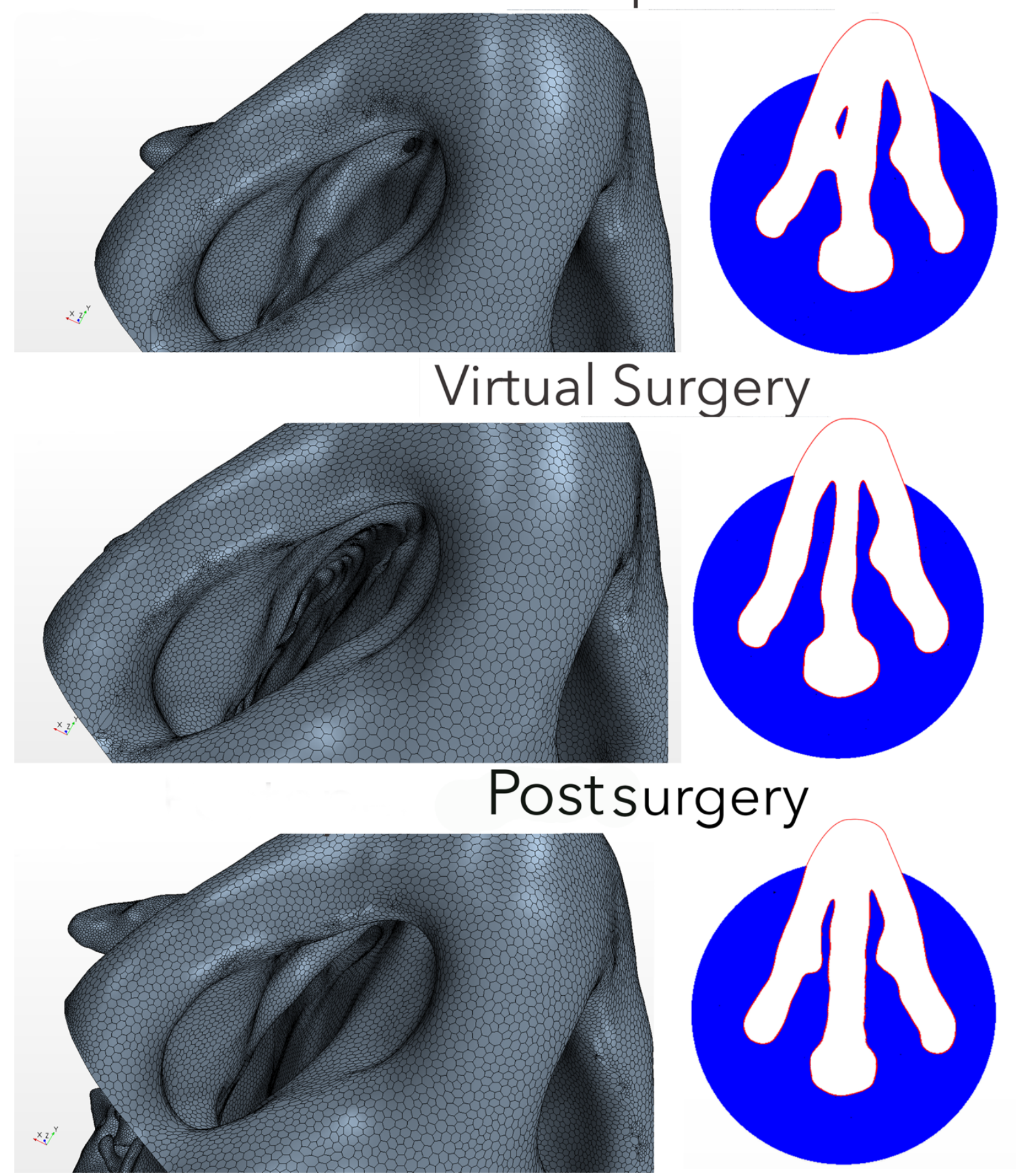

Figure 1. Comparison of surgeries for Patient 1. Three-dimensional anterior and right inferior views showing differences in the anterior part of the right nasal fossa after VS and PS compared to preoperative model. Nasal valve appeared slightly wider after VS than PS. 


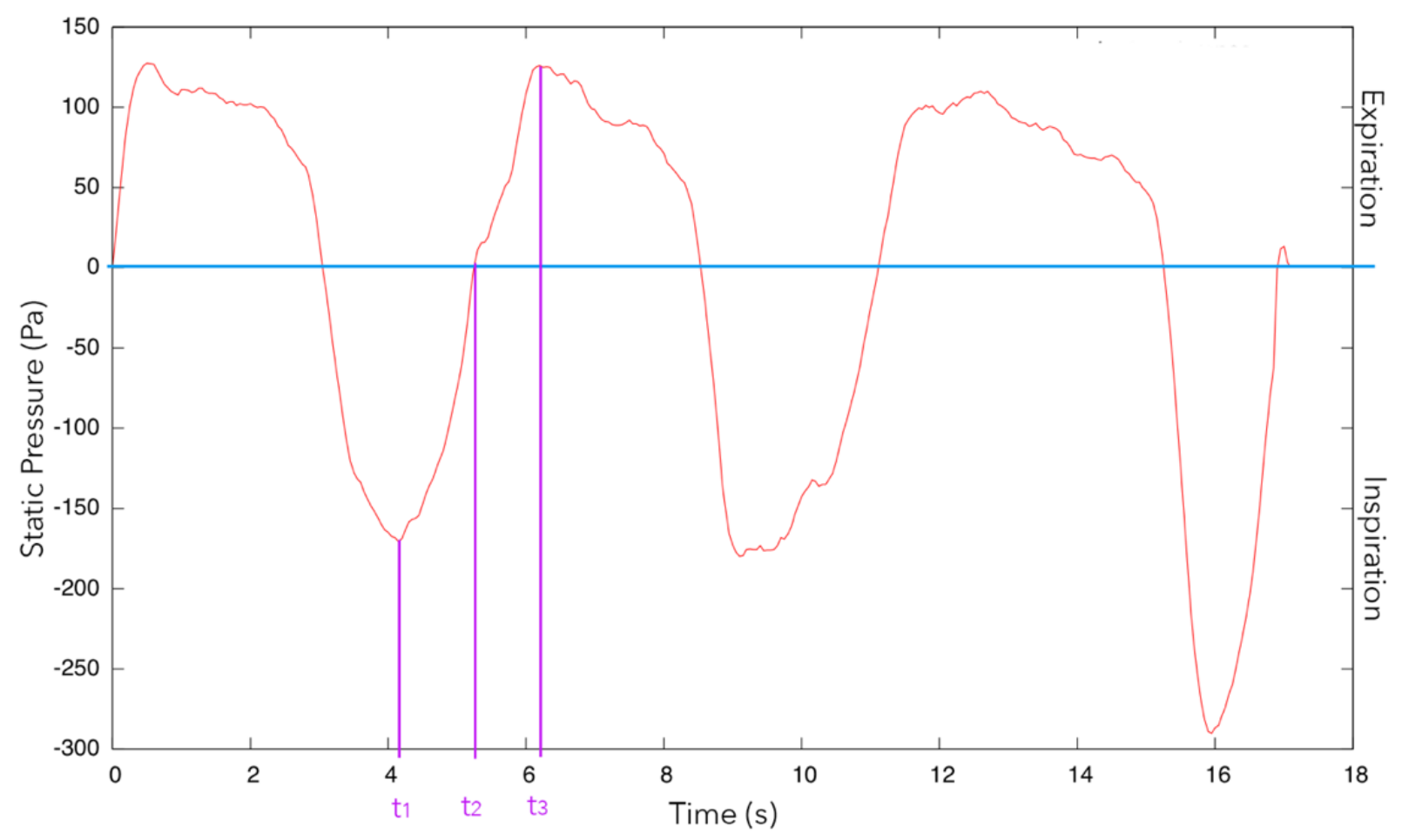

Figure 2. Breathing cycle used for unsteady computation: time-varying static pressure differential applied to nasopharynx. $\mathrm{t}_{1}$ was maximum inspiration $(\Delta \mathrm{P}=-171 \mathrm{~Pa}$, time $=4.15 \mathrm{sec})$, $t_{2}$ was the transition between inspiration and expiration $(\Delta \mathrm{P}=0 \mathrm{~Pa}$, time $=5.25 \mathrm{sec})$ and $\mathrm{t}_{3}$ was maximum expiration phase $(\Delta \mathrm{P}=+126 \mathrm{~Pa}$, time $=6.2 \mathrm{sec})$. 


\section{Preoperative Virtual Surgery Postsurgery}

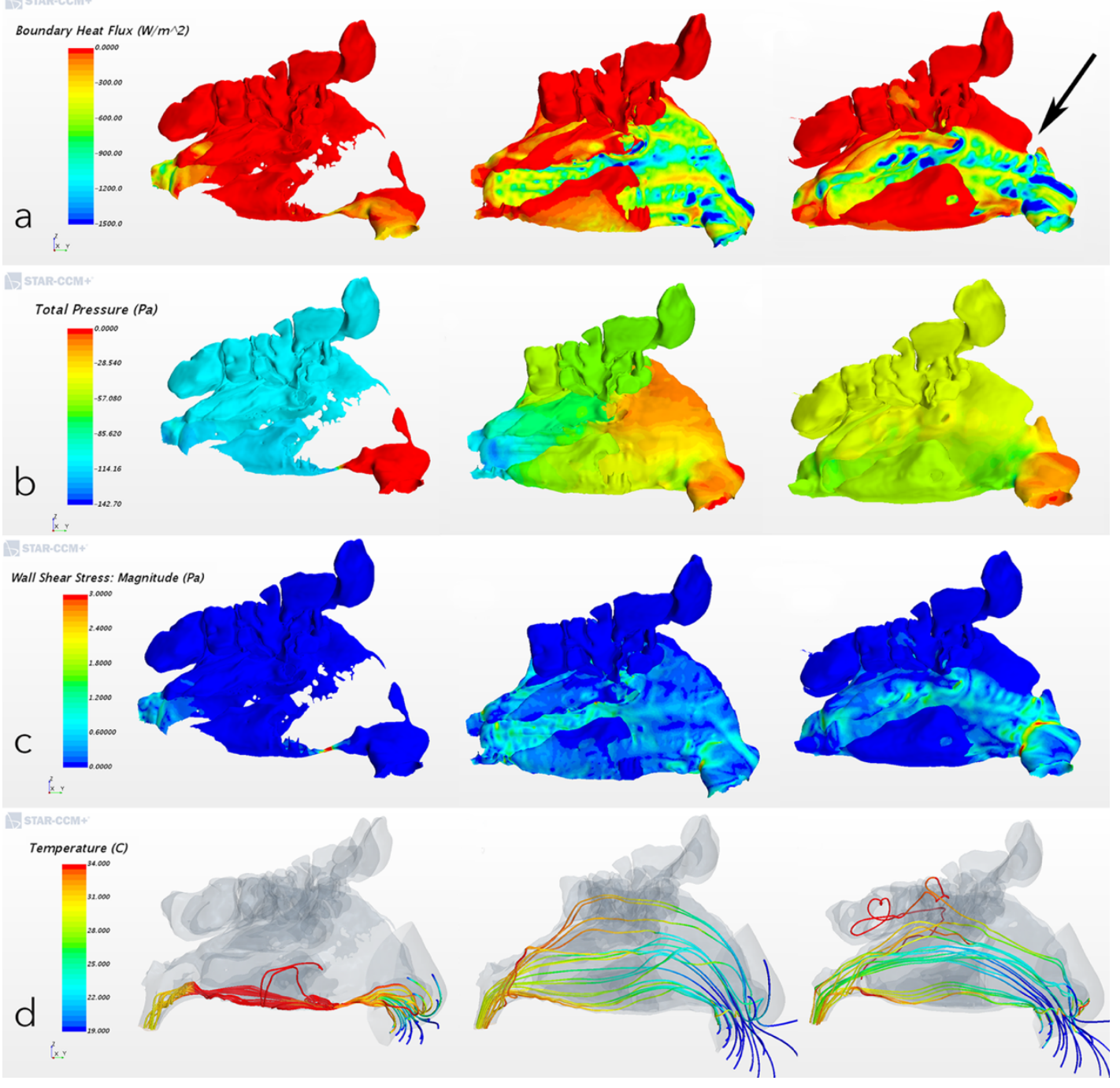

Figure 3. Computations during inspiration phase $\left(\mathrm{t}_{1}\right)$ for Patient 1 (right nasal fossa). We observe a. Heat flux $\left(\mathrm{W} / \mathrm{m}^{2}\right)$, b. Total Pressure (Pa), c. Wall Shear Stress (Pa) and d. Streamlines according to temperature $\left({ }^{\circ} \mathrm{C}\right)$. All variables were improved after VS or PS. The main difference between VS and PS was found on the upper part of the right nasal fossa. The black arrow on PS model shows the defect of correction in the upper part of the right nasal fossa compared to VS model. Streamlines repartitions also improved after surgeries. 


\section{Temperatures $\left({ }^{\circ} \mathrm{C}\right)$ for Patient 1 and 2}

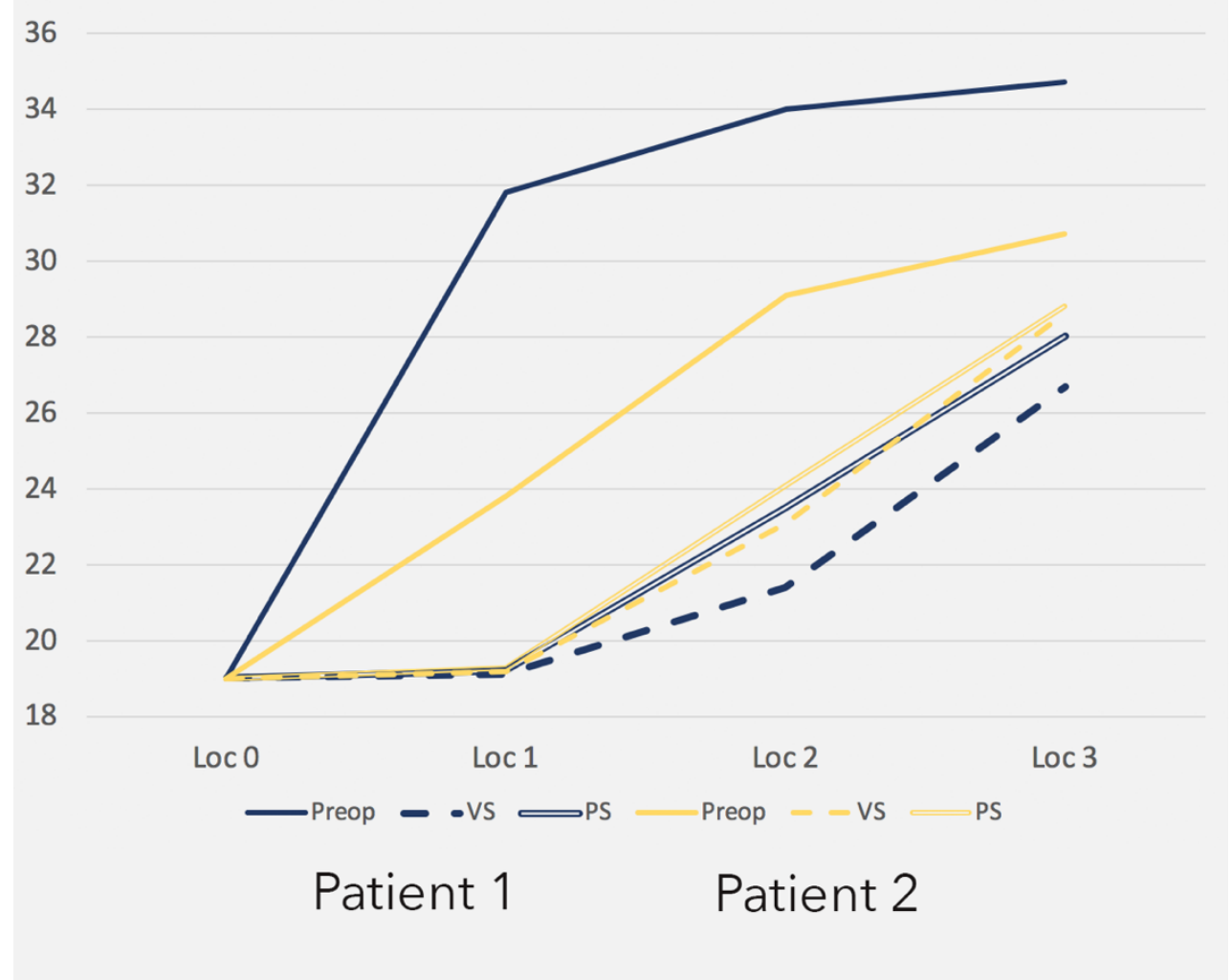

Figure 4. Evolution of temperatures for Patient 1 and Patient 2 before and after surgeries according to Location $n^{\circ} 1,2$ and 3 during inspiration. 


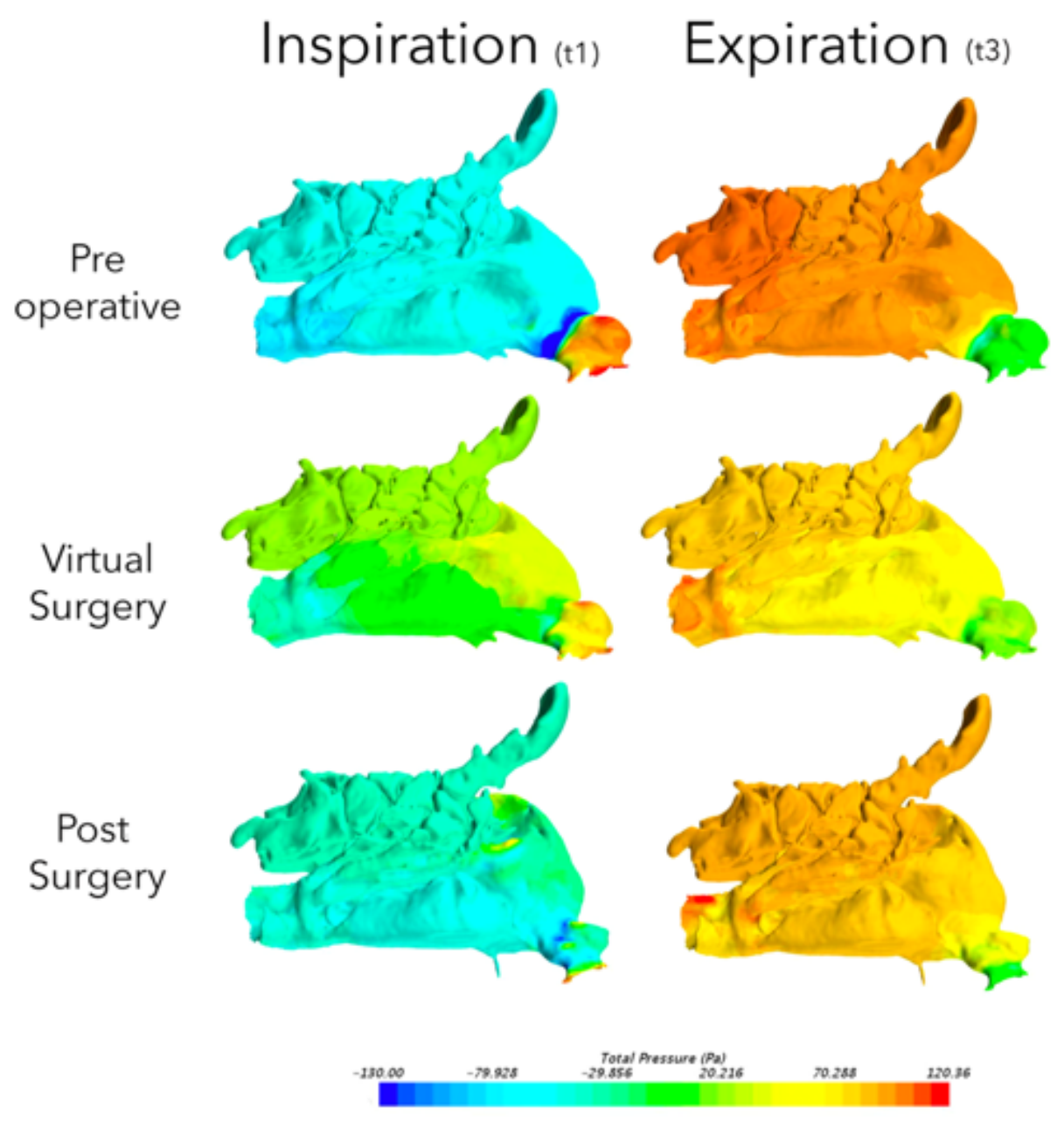

Figure 5. Right nasal fossa of Patient 2. Representation of total pressure before surgery and after VS and PS, according to inspiration and expiration phases. Before surgeries, a strong pressure drop was found regarding the nasal valve area. We observe an improvement at $t_{1}$ and $t_{3}$ especially regarding location $n^{\circ} 1$. During expiration phase, differences between models were not statistically significant. 


\section{Patient 1}
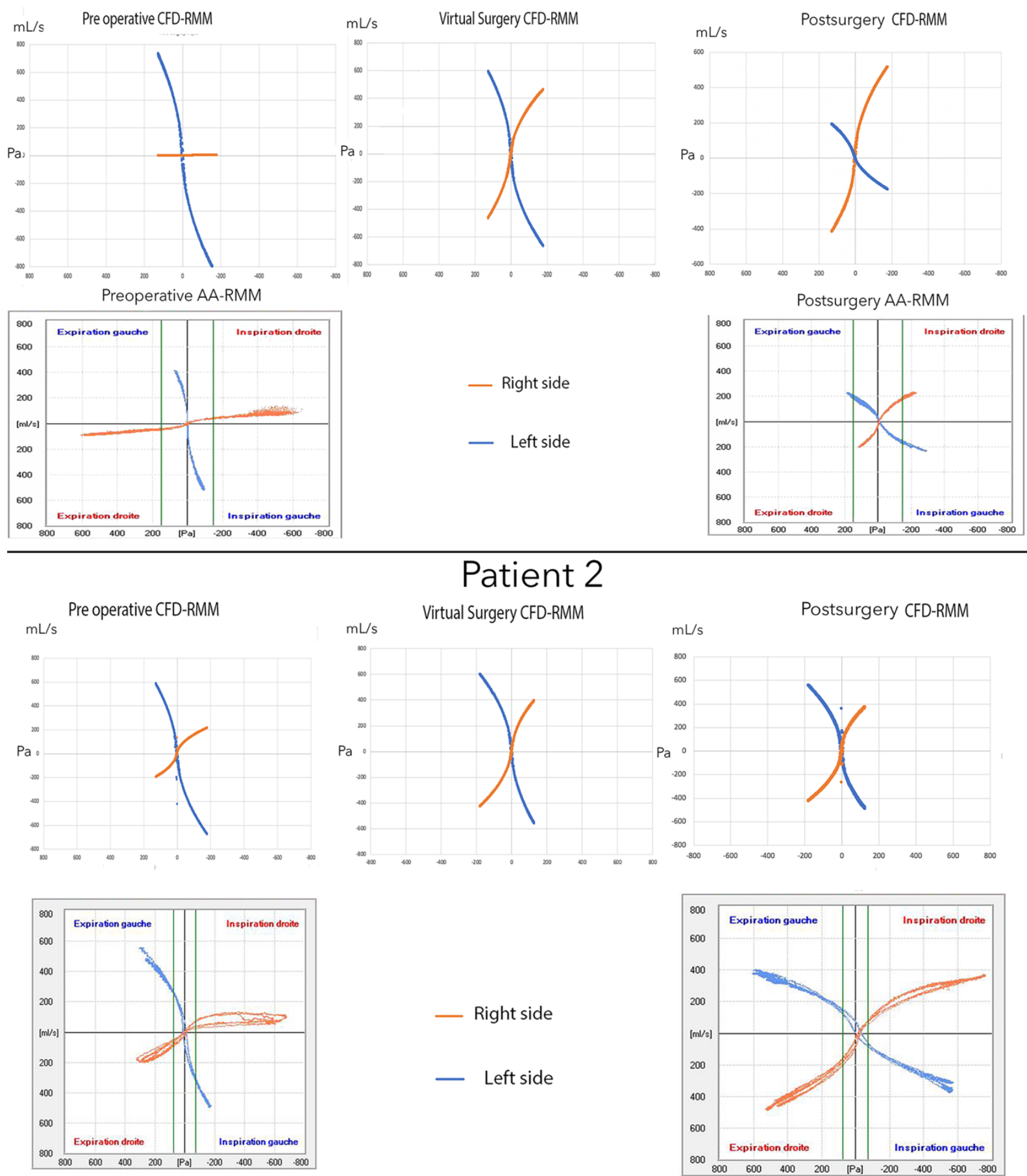

Figure 6. Comparison between CFD-RMM (top) and AA-RMM (bottom), before surgery and after VS and PS for Patient 1 and 2. The shapes of CFD-RMM and AA-RMM were comparable. VS and PS models provided the same results regarding the obstructed side (Red curves). 

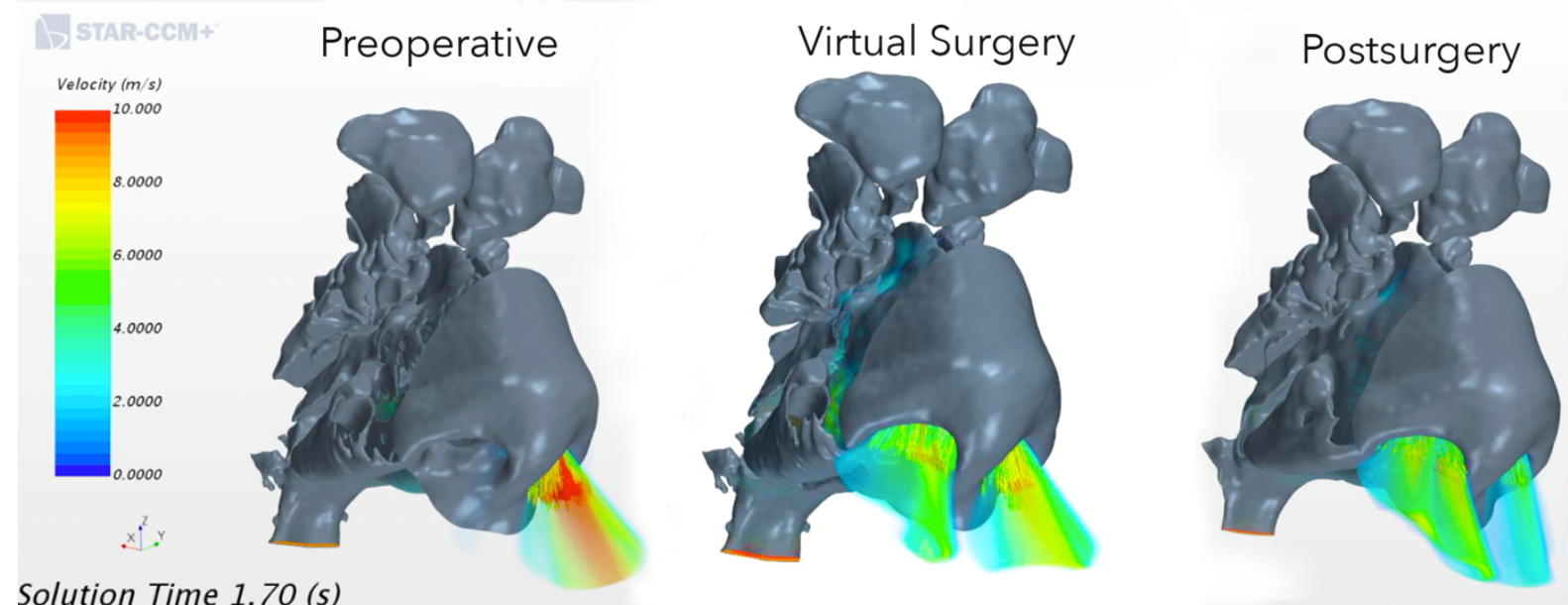

Solution Time $1.70(s)$

Figure 7. Visual comparison of airflow during expiration $\left(t_{3}\right)$ before and after surgeries for Patient 1. After surgeries (VS and PS), air distribution was more balanced between right and left nasal fossa. Colorimetric scale according to velocities.

Patient 2

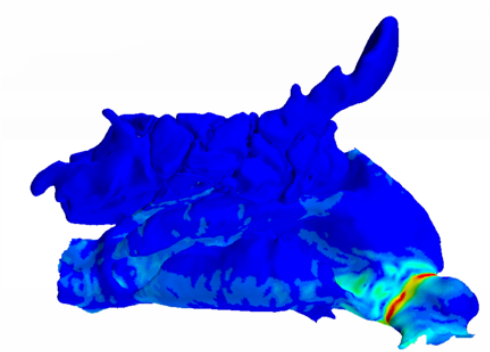

Preoperative

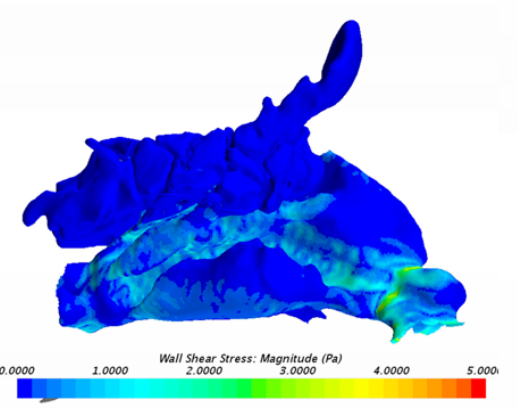

Virtual Surgery

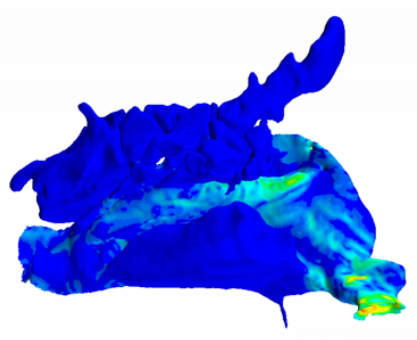

Postsurgery

Figure 8. Visualization of wall shear stress for patient 2. WSS values for Location $n^{\circ} 2$ and 3 are almost equal. 


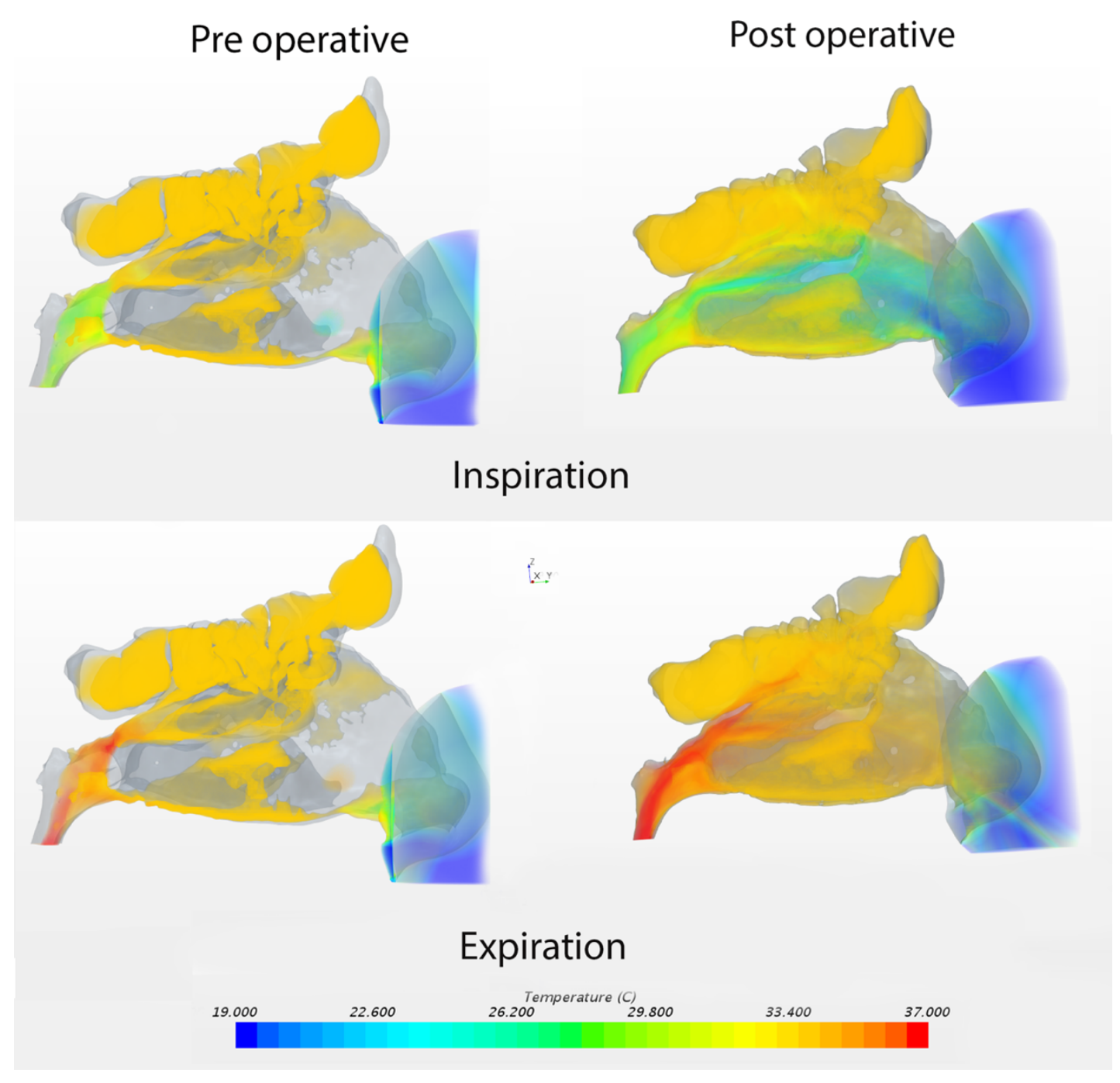

Video 1. Representation of Air temperature with unsteady flow in preoperative and PS model. After surgery, in inspiration, most of the airflow was on middle pathway. However, in expiration, air pathway was more balanced (upper, middle and inferior pathway).

\section{REFERENCES}

1. Osborn JL, Sacks R. Chapter 2: Nasal obstruction. Am J Rhinol Allergy. juin 2013;27 Suppl 1:S7-8.

2. Teixeira J, Certal V, Chang ET, Camacho M. Nasal Septal Deviations: A Systematic Review of Classification Systems. Plast Surg Int. 2016;2016:7089123.

3. Vogt K, Wernecke K-D, Behrbohm H, Gubisch W, Argale M. Four-phase 
rhinomanometry: a multicentric retrospective analysis of 36,563 clinical measurements. Eur Arch Oto-Rhino-Laryngol Off J Eur Fed Oto-Rhino-Laryngol Soc EUFOS Affil Ger Soc OtoRhino-Laryngol - Head Neck Surg. mai 2016;273(5):1185-98.

4. Leong SC. A review of the implications of computational fluid dynamic studies on nasal airflow and physiology. Rhinol J [Internet]. 1 juin 2010 [cité 22 oct 2018];48(2). Disponible sur: http://www.rhinologyjournal.com/abstract.php?id=878

5. Leite SHP, Jain R, Douglas RG. The clinical implications of computerised fluid dynamic modelling in rhinology. :8.

6. Radulesco T, Meister L, Bouchet G, Varoquaux A, Giordano J, Mancini J, et al. Correlations between Computational Fluid Dynamics and clinical evaluation of nasal airway obstruction due to septal deviation: an observational study. Clin Otolaryngol Off J ENT-UK Off J Neth Soc Oto-Rhino-Laryngol Cervico-Facial Surg. 20 avr 2019;

7. Kimbell JS, Frank DO, Laud P, Garcia GJM, Rhee JS. Changes in nasal airflow and heat transfer correlate with symptom improvement after surgery for nasal obstruction. $\mathrm{J}$ Biomech. oct 2013;46(15):2634-43.

8. Rhee JS. Role of Virtual Surgery in Preoperative Planning: Assessing the Individual Components of Functional Nasal Airway Surgery. Arch Facial Plast Surg. 1 sept 2012;14(5):354.

9. Frank-Ito DO, Kimbell JS, Laud P, Garcia GJM, Rhee JS. Predicting Postsurgery Nasal Physiology with Computational Modeling: Current Challenges and Limitations. Otolaryngol Neck Surg. nov 2014;151(5):751-9.

10. Quadrio M, Pipolo C, Corti S, Lenzi R, Messina F, Pesci C, et al. Review of computational fluid dynamics in the assessment of nasal air flow and analysis of its limitations. Eur Arch Otorhinolaryngol. sept 2014;271(9):2349-54.

11. Radulesco T, Hazbri D, Dessi P, Adalian P, Michel J. Geometric morphometric contribution to septal deviation analysis. Surg Radiol Anat [Internet]. 2 avr 2019 [cité 19 avr 2019]; Disponible sur: http://link.springer.com/10.1007/s00276-019-02235-6

12. Floyd EM, Ho S, Patel P, Rosenfeld RM, Gordin E. Systematic Review and Metaanalysis of Studies Evaluating Functional Rhinoplasty Outcomes with the NOSE Score. Otolaryngol--Head Neck Surg Off J Am Acad Otolaryngol-Head Neck Surg. 2017;156(5):809-15.

13. Spoor CF, Zonneveld FW, Macho GA. Linear measurements of cortical bone and dental enamel by computed tomography: applications and problems. Am J Phys Anthropol. août 1993;91(4):469-84.

14. Lindemann J, Tsakiropoulou E, Scheithauer MO, Konstantinidis I, Wiesmiller KM. Impact of menthol inhalation on nasal mucosal temperature and nasal patency. Am J Rhinol. août 2008;22(4):402-5.

15. Pawar SS, Garcia GJM, Rhee JS. Advances in Technology for Functional Rhinoplasty. Facial Plast Surg Clin N Am. mai 2017;25(2):263-70.

16. Di M-Y, Jiang Z, Gao Z-Q, Li Z, An Y-R, Lv W. Numerical Simulation of Airflow Fields in Two Typical Nasal Structures of Empty Nose Syndrome: A Computational Fluid Dynamics Study. Secomb TW, éditeur. PLoS ONE. 18 déc 2013;8(12):e84243.

17. Burgos MA, Sanmiguel-Rojas E, del Pino C, Sevilla-García MA, Esteban-Ortega F. New CFD tools to evaluate nasal airflow. Eur Arch Otorhinolaryngol. août 2017;274(8):3121-8.

18. Li C, Farag AA, Maza G, McGhee S, Ciccone MA, Deshpande B, et al. Investigation of the abnormal nasal aerodynamics and trigeminal functions among empty nose syndrome patients: Abnormal nasal aerodynamics in ENS patients. Int Forum Allergy Rhinol. mars 2018;8(3):444-52.

19. Lara-Sánchez H, Álvarez Nuño C, Gil-Carcedo Sañudo E, Mayo Iscar A, Vallejo 
Valdezate LÁ. Assessment of nasal obstruction with rhinomanometry and subjective scales and outcomes of surgical and medical treatment. Acta Otorrinolaringol Esp. juin 2017;68(3):145-50.

20. Patel RG, Garcia GJM, Frank-Ito DO, Kimbell JS, Rhee JS. Simulating the Nasal Cycle with Computational Fluid Dynamics. Otolaryngol-Head Neck Surg. févr 2015;152(2):353-60.

21. Gaberino C, Rhee JS, Garcia GJM. Estimates of nasal airflow at the nasal cycle midpoint improve the correlation between objective and subjective measures of nasal patency. Respir Physiol Neurobiol. avr 2017;238:23-32.

22. Vogt K, Bachmann-Harildstad G, Lintermann A, Nechyporenko A, Peters F, Wernecke KD. The new agreement of the international RIGA consensus conference on nasal airway function tests. Rhinol J. 1 juin 2018;56(2):133-43.

23. Hörschler I, Schröder W, Meinke M. On the assumption of steadiness of nasal cavity flow. J Biomech. avr 2010;43(6):1081-5.

24. Garcia GJM, Rhee JS, Senior BA, Kimbell JS. Septal Deviation and Nasal Resistance: An Investigation using Virtual Surgery and Computational Fluid Dynamics. Am J Rhinol Allergy. janv 2010;24(1):e46-53.

25. Hildebrandt T, Goubergrits L, Heppt W, Bessler S, Zachow S. Evaluation of the Intranasal Flow Field through Computational Fluid Dynamics. Facial Plast Surg. 5 avr 2013;29(02):093-8.

26. Shadfar S, Shockley WW, Fleischman GM, Dugar AR, McKinney KA, Frank-Ito DO, et al. Characterization of Postoperative Changes in Nasal Airflow Using a Cadaveric Computational Fluid Dynamics Model: Supporting the Internal Nasal Valve. JAMA Facial Plast Surg. 1 sept 2014;16(5):319.

27. Ozlugedik S, Nakiboglu G, Sert C, Elhan A, Tonuk E, Akyar S, et al. Numerical Study of the Aerodynamic Effects of Septoplasty and Partial Lateral Turbinectomy. The

Laryngoscope. févr 2008;118(2):330-4.

28. Hariri BM, Rhee JS, Garcia GJM. Identifying patients who may benefit from inferior turbinate reduction using computer simulations: Patients Who Benefit From Turbinectomy. The Laryngoscope. déc 2015;125(12):2635-41.

29. Dayal A, Rhee JS, Garcia GJM. Impact of Middle versus Inferior Total Turbinectomy on Nasal Aerodynamics. Otolaryngol Neck Surg. sept 2016;155(3):518-25.

30. Rhee JS. Toward Personalized Nasal Surgery Using Computational Fluid Dynamics. Arch Facial Plast Surg. 1 sept 2011;13(5):305.

31. de Gabory L, Reville N, Baux Y, Boisson N, Bordenave L. Numerical simulation of two consecutive nasal respiratory cycles: toward a better understanding of nasal physiology: Simulation of nasal physiology. Int Forum Allergy Rhinol. juin 2018;8(6):676-85.

32. Balakin BV, Farbu E, Kosinski P. Aerodynamic evaluation of the empty nose syndrome by means of computational fluid dynamics. Comput Methods Biomech Biomed Engin. 26 oct 2017;20(14):1554-61.

33. Bonaparte JP, Campbell R. Assessment of Pliability and Elasticity of the External Nasal Skin in Patients With Unilateral Nasal Valve Collapse: A Static Biomechanical Evaluation. JAMA Facial Plast Surg. 1 déc 2018;20(6):475.

34. Griffin M, Premakumar Y, Seifalian A, Butler PE, Szarko M. Biomechanical Characterization of Human Soft Tissues Using Indentation and Tensile Testing. J Vis Exp [Internet]. 13 déc 2016 [cité 19 avr 2019];(118). Disponible sur:

http://www.jove.com/video/54872/biomechanical-characterization-human-soft-tissues-usingindentation

35. Miyanawala TP, Jaiman RK. An Efficient Deep Learning Technique for the NavierStokes Equations: Application to Unsteady Wake Flow Dynamics. 25 oct 2017 [cité 25 avr 
2019]; Disponible sur: https://arxiv.org/abs/1710.09099v3 